Florida International University FIU Digital Commons

$11-9-2005$

\title{
Children's learning of anxiety sensitivity : a preliminary study using a sample of youths referred for anxiety disorders
}

Claudia I. Alvarez de Lugo

Florida International University

DOI: $10.25148 /$ etd.FI14030203

Follow this and additional works at: https://digitalcommons.fiu.edu/etd

Part of the Psychiatry and Psychology Commons

\section{Recommended Citation}

Alvarez de Lugo, Claudia I., "Children's learning of anxiety sensitivity : a preliminary study using a sample of youths referred for anxiety disorders" (2005). FIU Electronic Theses and Dissertations. 1051.

https://digitalcommons.fiu.edu/etd/1051 


\section{FLORIDA INTERNATIONAL UNIVERSITY}

Miami, Florida

CHILDREN'S LEARNING OF ANXIETY SENSITIVITY: A PRELIMINARY STUDY USING A SAMPLE OF YOUTHS REFERRED FOR ANXIETY DISORDERS

A thesis submitted in partial fulfillment of the

requirements for the degree of

MASTER OF SCIENCE

in

PSYCHOLOGY

by

Claudia I. Alvarez de Lugo 
To: Interim Dean Mark Szuchman

College of Arts and Sciences

This thesis, written by Claudia I. Alvarez de Lugo, and entitled Children's Learning of Anxiety Sensitivity: A Preliminary Study using a Sample of Youths Referred for Anxiety Disorders, having been approved in respect to style and intellectual content, is referred to you for judgment.

We have read this thesis and recommend that it be approved.

William Kurtines

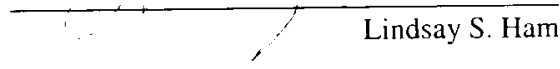

Wendy K. Silverman, Major Professor

Date of Defense: November 9, 2005

The thesis of Claudia I. Alvarez de Lugo is approved.

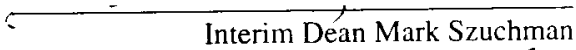

College of Arts and 8 ciforces

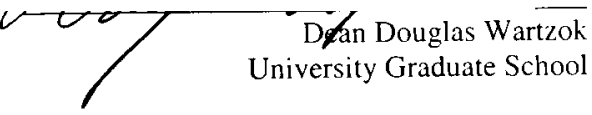

Florida International University, 2005 


\section{DEDICATION}

I dedicate this thesis to Dani and Isa for waiting with patience and understanding during those days that I have been absent. 


\section{ACKNOWLEDGEMENT}

I wish to thank the members of my committee, William Kurtines, Lindsay Ham, and my major professor Wendy K. Silverman, for all their support, advice, and attention given to my work. They have helped me go through this exercise, which represents one step of an upcoming professional career.

I specially want to thank my major professor and mentor Wendy K. Silverman for her vision, clarity, precision, pragmatism, and humor. Her presence has been essential in the development of this project and in our everyday journey of helping children and their families.

I would like to thank Armando A. Pina for his unconditional support and guidance. I greatly thank my husband, my daughter, family, and friends for their infinite love. patience, and support. 


\section{ABSTRACT OF THE THESIS}

\section{CHILDREN'S LEARNING OF ANXIETY SENSITIVITY: A PRELIMINARY STUDY}

USING A SAMPLE OF YOUTHS REFERRED FOR ANXIETY DISORDERS

by

\section{Claudia I. Alvarez de Lugo}

Florida International University, 2005

Miami, Florida

Professor Wendy K. Silverman, Major Professor

The purpose of the present study was to examine the origins of anxiety sensitivity (AS) by assessing youths' learning experiences in relation to their AS symptoms and anxiety symptoms. Participants were 33 youths between 7 to 13 years old $(M=9.39$ years, $S D=2.01)$. Youths were assessed using a structured interview and self-report measures. Chi-square analyses revealed no statistically significant differences in the proportions of boys vs. girls, Hispanic vs. non-Hispanic, and married vs. non-married. Pearson correlation analyses revealed that youths' AS learning experiences were significantly related to youths' AS and to youths' anxiety symptoms scores. Partial correlations between youths' learning experiences associated with AS symptoms in relation to AS scores controlling for anxiety symptoms effects were statistically significant. Findings were consistent with theory and suggest that learning mechanisms may be involved in AS acquisition and maintenance. The findings' implications are discussed regarding possible learning experiences' role in the development of AS. 
CHAPTER

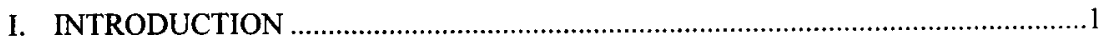

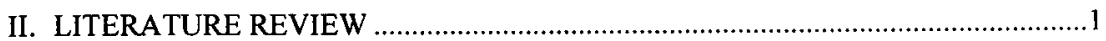

Anxiety Sensitivity and Anxiety Disorders ........................................................... 1

Anxiety Sensitivity and Its Possible Etiological Factors ......................................... 2

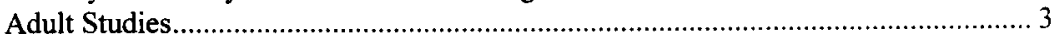

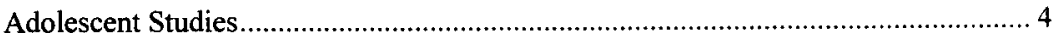

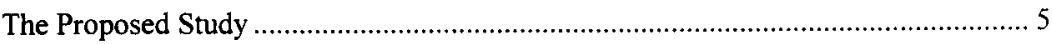

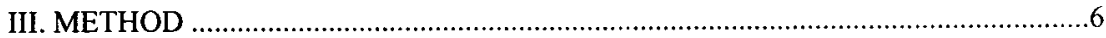



Diagnostic Interview Schedule …................................................................... 7

Child-Completed Measures ............................................................................... 8

Assessment of Children's Learning of Anxiety Sensitivity ......................................... 9

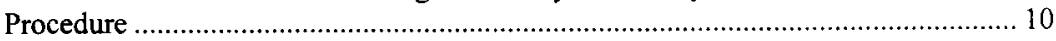

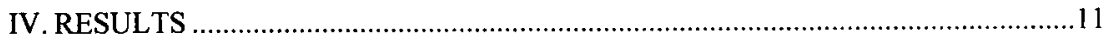

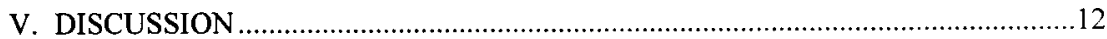

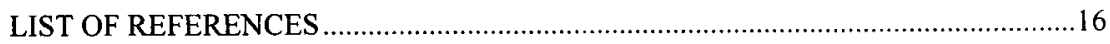

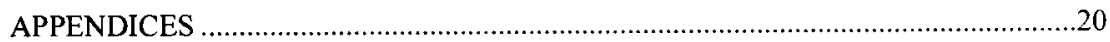


Anxiety disorders are the most prevalent internalizing disorders in youths and negatively impact youths' academic and interpersonal functioning (Keller et al., 1992; Silverman \& Ginsburg, 1998). In anxiety disorders theory and research, anxiety sensitivity (AS) has been identified as a risk factor in the development of anxiety and its disorders (e.g., Hayward, Killen, Kraemer, \& Taylor, 2000; Maller \& Reiss, 1992; Reiss, 1991; Schmidt, Lerew, \& Jackson, 1997, 1999).

Reiss (1991) proposed an expectancy model that describes two variables that motivate humans' avoidance of feared objects: expectation (i.e., thoughts about encountering the feared object) and sensitivity (i.e., the reason why individuals are afraid of the feared object or event). The expectancy model of AS explains fear in terms of three categories: (1) expectation of danger or injury, (2) expectation of anxiety, and (3) expectation of negative social evaluations. Accordingly, individuals are afraid because they anticipate danger from the environment; they anticipate panic attacks or consequences of physiological changes (e.g., racing heart); and they anticipate embarrassment. Anxiety sensitivity refers to beliefs that anxiety-related somatic/physiological sensations (e.g., feeling shaky, increased heart rate, trembling. shortness of breath) have severe negative social, cognitive, and physical consequences. Anxiety Sensitivity and Anxiety Disorders

Given the accumulating evidence for the role of AS as a risk factor for anxiety disorders, further understanding of AS can serve to inform anxiety prevention and treatment intervention research. Unfortunately, there is little empirical information about mechanisms relating to the development of AS in adults. The research literature about mechanisms relating to the onset of AS in children and adolescents is even more scant. 
To assess individual differences in AS in children, Silverman and colleagues developed the Childhood Anxiety Sensitivity 1ndex (CASI) (Silverman, Fleisig, Rabian, \& Peterson, 1991). A number of factor analytical studies support a hierarchical factor structure of AS (Muris, Schmidt, Merckelbach, \& Schouten, 2001; Silverman, Ginsburg, \& Goedhart, 1999; van Widerfelt, Siebelink, Goedhart, \& Treffers, 2002). Silverman, Goedhart, Barrett, and Turner (2003) recently clarified the facets of AS represented by the CASI to select the "best" model and evaluated the consistency of the AS model across age and sex. They found evidence for a hierarchical model of AS with four facets: Disease Concerns, Unsteady Concerns, Mental Incapacitation Concerns, and Social Concerns. This finding suggests that children with high AS may be easily frightened and may acquire beliefs that anxiety sensations lead to experiencing disease, unsteadiness, loss of control, and/or embarrassment.

Anxiety Sensitivity and Its Possible Etiological Factors

Reiss and McNally (1985) stated that high levels of physiological arousal increase the risk for developing high levels of AS. Although genetic factors play a role in individuals' arousability (Stein, Jang, \& Livesley, 1999), learning mechanisms also likely play an etiological role (Schmidt, Lerew, \& Joiner, 2000; Watt, Stewart, \& Cox, 1998). These learning mechanisms include operant conditioning (e.g., parental positive and negative reinforcement of physiological symptoms), modeling (e.g., parental physiological symptoms that can be imitated), and information transfer through verbal interaction (Ehlers, 1993). Discerning the relation between these learning mechanisms and the development of AS in a child and adolescent sample has not received research attention. This represents the main aim of the present study. 


\section{Adult Studies}

In the adult research area, Whitehead, Busch, Heller, and Costa (1986) used the Menstrual History Questionnaire to assess retrospectively the relation between positive/negative reinforcement and physiological symptom experiences relating to menstrual and cold symptoms in 351 female college students between 18 to 39 years ( $M$ $=25.2$ years). Number and severity of physiological symptoms were significantly correlated with maternal encouragement and modeling of a sick role for menstrual symptoms during adolescence. In a subsequent study, using a nonclinical sample of 340 women between 20 to 40 years, Whitehead et al. (1992) revised the Menstrual History Questionnaire (Whitehead et al., 1986) by adding items relating to bowel and cold symptoms to assess retrospectively childhood learning illness behaviors. Whitehead et al. confirmed five scales related to childhood social learning of these symptoms: (1) modeling of menstrual symptoms, (2) parental encouragement of menstrual symptoms, (3) modeling of bowel symptoms, (4) parental encouragement of bowel symptoms, and (5) encouragement of cold symptoms.

Ehlers (1993) adapted the Menstrual History Questionnaire to develop the Learning History Questionnaire (LHQ; Ehlers, 1993) to assess the relation between childhood learning experiences relating to panic-like symptoms and cold symptoms as well as fear of AS bodily sensations and catastrophic cognitions. Based on the retrospective reports of a clinical sample of 306 adults ages 18 to 64 years ( $M$ and $S D$ for the total sample were not reported; 225 female, 121 had panic disorder, 86 infrequent panic attacks, 38 other anxiety disorders, and 61 controls), Ehlers found that childhood learning experiences associated with panic-like symptoms were significantly more 
positively and negatively reinforced by parents of participants with panic and other anxiety disorders than parents of control participants.

Watt and Stewart (2000) expanded the LHQ to examine in a sample of 197 undergraduate students $(M=21.9$ years, $S D=4.6 ; 154$ female) childhood learning experiences of panic-like symptoms (e.g., increased heart beat, shortness of breath) and pain symptoms (e.g., stomachaches, lumps) and their relation to current AS levels. Significant positive relations were found between childhood learning experiences associated with panic-like and pain symptoms and with levels of AS. Stewart et al. (2001) further evaluated the potential role of AS as a mediator of participants' retrospective accounts of their childhood learning experiences and current panic attacks in an independent sample of 478 university students ( $M=21$ years, $S D=3$ years; 317 female). Results indicated that AS mediated the relation between learning experiences for paniclike symptoms during childhood and panic attacks in young adults. Again, retrospective accounts of childhood learning experiences were significantly positively correlated with AS in young adults. These findings suggest that young adults' high levels of AS may be influenced directly by having learned a way to catastrophize the meaning of somatic symptoms in general (Stewart \& Watt, 2000).

\section{Adolescent Studies}

In the adolescent research literature, only one study has examined the relation between adolescents' learning experiences of panic-like symptoms and pain symptoms and their AS. In Muris, Marckelbach, and Meesters (2001), a Dutch version of the LHQ adapted for use with adolescents was used to assess learning experiences in a school sample of 52 adolescents (ages 12 to 14 years; $M=12.3$ years, $S D=0.5,29$ girls). 
Learning experiences were examined in terms of parental positive reinforcement (e.g., When you feel dizzy, do your parents allow you to stay home from school?), parental verbal transmission of information (e.g., When you feel dizzy, do your parents warn you of the possible danger of the symptoms?), and parental modeling (e.g., does he/she stay home from work when he/she suffers from these symptoms?). A statistically significant correlation was found between parental transmission of information of panic-like symptoms and adolescents' levels of AS, but not between parental positive reinforcement of panic-like symptoms or parental modeling of panic-like symptoms and adolescents" levels of AS.

\section{The Proposed Study}

The purpose of this thesis was to further explore learning factors that have been found to be related to the onset and maintenance of AS in children. Since previous research has used retrospective accounts of adult participants to assess their childhood learning experiences of physiological symptoms in relation to their current AS (Ehlers, 1993; Stewart et al., 2001; Watt \& Stewart, 2000), this study assessed youths' learning experiences using ongoing reports. Retrospective accounts are, likely, to be biased and less valid because they are influenced by the participants' selective memory.

The first goal of the present study was to develop a set of questions, providing children and adolescents with the opportunity to respond to current situations specific to AS symptoms, such as fear of loss cognitive control, fear of physical arousal, and fear of embarrassment. Previous studies assessed learning experiences specific to physiological symptoms (i.e., menstrual, bowel, cold, panic-like, and pain symptoms), but did not include all AS facets. 
The second goal was to examine youths' learning experiences relevant to all the facets of AS (i.e., disease, unsteadiness, loss of control and/or embarrassment) in addition to physiological symptoms (e.g., panic-like symptoms). The third goal was to examine the relation between youths' learning experiences of AS and AS, while controlling for anxiety symptoms assessed by the Revised Children's Manifest Anxiety Scale (RCMAS) (Reynolds \& Richmond, 1978). This allowed us to examine if participants' anxiety symptoms were influencing the relation between children's learning experiences and their AS scores.

Guided by Reiss' model (1991), social learning theory (see Rachman, 1977) and the research by Stewart et al. (2001), three main hypotheses were investigated.

Hypothesis \# 1: Youths' scores of learning experiences of AS would be significantly correlated with scores of AS (Learning experiences questions-CASl relation).

Hypothesis \# 2: Youths' scores of learning experiences of AS would be significantly correlated with scores of anxiety symptoms (Learning experiences questions-RCMAS relation).

Hypothesis \# 3: Youths' scores of learning of AS would be significantly correlated with scores of AS beyond its relation to anxiety symptoms (Learning experiences questionsCASI relation controlling for the RCMAS).

\section{Method}

\section{Participants}

Participants were 33 youth and their parents ( $97 \%$ mothers) who presented to the Child and Family Psychosocial Research Center, Child Anxiety and Phobia Program at Florida International University, Miami. School counselors, mental health professionals, 
and pediatricians referred participants to the program; some participants were selfreferred. The sample was comprised of 20 boys and 13 girls, ages ranging from 7 to 13 years old $(M=9.39$ years, $S D=2.01)$. Sixty-four percent $(n=21)$ of the sample was Hispanic/Latino (self-reported), $12 \%(n=4)$ was White European American (selfreported). $9 \%(n=3)$ was African American (self-reported), and $15 \% .(n=5)$ was mixed or unreported ethnicity (self-reported). Forty-eight percent $(n=16)$ of the sample reported both parents were Hispanic/Latino. These 16 families represented five different Hispanic/Latin countries as the family`s country of origin (e.g., Cuba, Nicaragua, Colombia, Peru, and Honduras).

Most children met DSM-IV criteria for primary anxiety disorder diagnoses. $82 \%$ $(n=27)$; separation anxiety disorder, $33 \%(n=11)$; social phobia, $18.2 \%(n=6)$ : generalized anxiety disorder, $15.2 \%(n=5)$; specific phobia, $9.1 \%(n=3)$; and obsessive compulsive disorder, $6.1 \%(\mathrm{n}=2)$ using the Anxiety Disorders Interview Schedule for Children for DSM-IV (ADIS-IV: C/P; Albano \& Silverman, 1996). Eighty-eight percent $(n=29)$ of the sample reported comorbid diagnoses (e.g., anxiety disorders, dysthymic disorder, and attention-deficithyperactivity disorder). Exclusionary criteria for participation were developmental delays (e.g., mental retardation. autism) and severe psychopathology (e.g., schizophrenia). Screening for these criteria was accomplished through a standardized telephone screen used at the center. Additional screening sections are contained on the interview schedule.

Diagnostic Interview Schedule

ADIS-IV: C/P (Albano \& Silverman, 1996). The ADIS-IV: C/P is a semistructured diagnostic interview that emphasizes anxiety disorders and other major 
childhood disorders according to DSM-IV criteria. Test-retest reliability of diagnoses using the ADIS-IV: C/P has been evaluated using an interval of 7 to 14 days. Results indicated that diagnoses derived using the ADIS-IV: C/P are reliable (Silverman, Saavedra, \& Pina, 2001). Kappa coefficients for separation anxiety disorder, social phobia, specific phobia, and generalized anxiety disorder were reported in the excellent range $(k=.80$ to .92$)$.

\section{Child-Completed Measures}

Childhood Anxiety Sensitivity Index (CASI; Silverman et al., 1991). The CASI is an 18-item self-report measure designed to assess the extent that children and adolescents view the experience of anxiety-related somatic/physiological symptoms as distressing. Children rate each question by using a 3-point scale: None (1), Some (2), or $A$ lot (3) with scores ranging from 18 to 54 . Silverman et al. (1991) reported an alpha coefficient of .87 and retest reliability estimates of .76 with a clinical sample of children with anxiety. The CASI has been shown to be a valid measure of AS in both children and adolescents (Weems, Hammond-Laurence, Silverman, \& Ginsburg, 1998). The CASI total score was used in this study. Examples of items from the CASl include, "It scares me when 1 feel like I am going to faint" and "It scares me when I have trouble getting my breath." Alpha coefficient for internal consistency in this sample was .82 for the total score.

Revised Children's Manifest Anxiety Scale (RCMAS; Reynolds \& Richmond, 1978). The RCMAS is a 37 -item child self-rating scale designed to assess anxiety symptoms in children and adolescents. The thirty-seven items are summed yielding a Total Anxiety score; each item is rated either Yes (1) or No (0). The RCMAS has three anxiety subscales and a lie scale, which will not be used in the present study. Reynolds 
and Richmond (1978) reported an alpha coefficient of 0.80 for the Total Anxiety scale with a community sample. Pela and Reynolds (1982) reported a 3-week interval retest reliability of .98 , also in a community sample. Estimates of concurrent validity for the RCMAS have been found to range from $(r \mathrm{~s}) .65$ to .76 (Lee, Piersel, Friedlander, \& Collamer, 1988). Examples of the items contained on this scale are "Often I feel sick in my stomach," and "I am tired a lot." An alpha coefficient for internal consistency of .87 was obtained with this sample.

Assessment of Children's Learning of Anxiety Sensitivity

Training of assessors. Ten questions were asked by a group of female undergraduate research assistants under the direction of a graduate student. A 20 minute, one-on-one training period preceded the data collection to facilitate standardization of the questions' administration. Training consisted of giving instructions. modeling procedures, and practicing with feedback.

Description of the learning experiences questions. Ten questions were designed to assess situations where parental encouragement of children's AS symptoms can occur (see Appendix A). These questions inquired about children's learning experiences based on their self-reported AS using the CASI (Silverman et al., 1991). Each item was written to reflect situations where positive/negative reinforcement or verbal transmission of information can occur (see Table 1). The items endorsed by the child on the CASI as "A lot" were used to further inquire about the child's learning experiences within the context of these CASI items. For example, if a child endorsed "It scares me when I feel shaky" on the CASI, then one of the items asked to the child was "When you feel shaky and get scared, do you skip your schoolwork, homework, or jobs around the house?" Another 
item was "When you feel shaky and get scared, do your parents tell you that you can get really sick because you feel this way?" Children responded to each item by using a 3point scale: None (1), Some (2), or A lot (3). The set of questions was read verbatim to the children by a trained research assistant.

Analysis of each question was conducted using the "Flesch-Kincaid Grade Level" reading level score. Modifications were made based on each item's Flesch-Kincaid Grade Level score. After, modifications were made, items were presented to a pilot sample of youth ( $N=5$, ages 7 to 13 years old) to ensure each item's comprehensibility. After additional modifications were made based on this small pilot, the Flesh-Kincaid Grade Level score on the set of questions was 4.3, suggesting that the questions were generally for those with at least a 4th grade reading level. Moreover, the Flesch Reading Ease score was high (i.e., 84.1; see Flesch, 1948; Thomas, Hartley, \& Kincaid, 1975). On a 100point scale, the higher the score, the easier it is to understand the document.

\section{Procedure}

Prior to the initial assessment, parents and children were provided with written and verbal explanations of the procedures and were asked to sign an informed consent/assent. At the initial intake, the child and one parent were interviewed by graduate students using the Anxiety Disorders Interview Schedule for DSM-IV: Child and Parent versions (ADIS-IV: C/P; Albano \& Silverman, 1996). While the child was being interviewed, the parent completed a questionnaire battery concerning his/her child's anxiety. After the child's interview was completed, the parent was interviewed, while the child completed a questionnaire battery that included the RCMAS, the CASI, and the learning experiences questions. The battery was administered by either trained 
graduate or advanced undergraduate research assistants. Before completing each instrument, instructions were read aloud to the children and examples were provided.

\section{Results}

Chi-square analyses were conducted to evaluate statistically significant differences in the proportions of gender (boys and girls), ethnicity (Latino, European American), and family income ( $\$ 0$ to $\$ 20,000, \$ 20,001$ to $\$ 40,000, \$ 40,001$ and over). Difference in the proportions of boys versus girls, Latino versus European American and proportions corresponding to these income categories were not statistically significant from each other. The internal consistency estimate for the total set of learning questions was .73 .

For AS (CASI), the mean score was $35.24(S D=6.46)$. For the learning experiences questions the mean score was $17.58(S D=3.99)$. For the RCMAS Total Anxiety scale, the mean score was $15.32(S D=6.45)$. Response frequencies, mean scores, and standard deviations for the learning experiences, and correlation coefficient between learning experiences questions and the CASI scores are shown in Table 2.

Response frequencies of learning experiences questions indicated that two of the three verbal transmission of information items and two of the positive reinforcement items were endorsed as "A lot" by at least one third of participants. All three of the negative reinforcement items were endorsed as "A lot" by less that one tenth of participants.

Pearson correlations were computed to test the hypothesis that the learning experiences questions scores would be significantly correlated with scores of AS (CASI). The correlation was statistically significant $(r=.53, p<0.01)$. 
Pearson correlations were computed to test the hypothesis that the learning experiences questions scores would be significantly correlated with scores of anxiety symptoms scores (RCMAS). The correlation was not statistically significant $(r=.087, p$ $<.64)$.

Pearson correlations were computed to test the hypothesis that the learning experiences questions would be significantly correlated with the AS scores (CASI) controlling for anxiety symptoms scores (RCMAS) and the partial correlation was statistically significant $(r=.55, p<0.05)$.

\section{Discussion}

The main findings showed that youths' learning of AS symptoms scores (i.e., assessed using the learning experiences questions) significantly related to youths' AS scores. Specifically, participants with higher AS scores reported having experienced significantly more learning experiences associated with AS symptoms. In examining youths' anxiety symptoms scores (i.e., anxiety symptoms assessed using the RCMAS) and anxiety sensitivity scores (i.e., anxiety sensitivity assessed using the CASI), correlation analysis revealed a significant association. No significant gender differences were found for the CASI, learning experience questions, or RCMAS scores.

These findings are consistent with past research results. Although previous studies using clinic-anxious adults (Ehlers, 1993) and nonclinical adults (e.g., Stewart et al., 2001; Watt \& Stewart, 2000) assessed participants' childhood learning experiences of physiological symptoms in relation to AS scores; the present study is the first to examine learning experiences associated with AS symptoms and AS scores in a sample of youths, in general, and in a clinical sample of anxious youths, in particular. Only one study used 
a non-clinical adolescent sample (Muris, Marckelbach, \& Meesters, 2001) to examine learning experiences associated with physiological symptoms in association with AS scores. Muris et al. found one type of learning mechanism (i.e., verbal transmission of information) was associated with physiological symptoms as significantly associated with AS scores.

The findings further suggested that verbal transmission of information is an important mechanism in the development of AS learning experiences. Negative reinforcement, in contrast, may be a less important learning mechanism. Three additional items (two positive reinforcement and one verbal transmission of information) were significantly associated with AS scores. Youth with higher AS tended to more frequently avoid homework, housework or schoolwork situations and to have parents who worry about their AS symptoms, and are brought to the doctor and given medicine.

The present study contributes to the existing literature because it is the first to directly examine youths' learning experiences associated with AS symptoms, not just physiological symptoms. Even though past findings have indicated that physiological symptoms relate to AS scores, studying participants' AS learning experiences in particular allows for exploring youths' learning experiences in relation to their fear of loss cognitive control, fear of physical arousal, and fear of embarrassment to understand how AS learning experiences relate to AS acquisition.

Exploring learning experiences of AS was important because AS might be mediating the relation between learning experiences and panic attacks in adults as studies suggest (Stewart et al., 2001; Watt \& Stewart, 2000). Social learning mechanisms appear to contribute to AS acquisition. Bouton, Mineka, and Barlow (2001) commented that the 
understanding of basic behavioral and cognitive processes underlying anxiety and panic disorders has advanced considerably. However, empirical research on AS onset has lagged behind.

The study's findings supported the notion that parental behavior plays a role in the learning process of AS. This has potential theoretical implications because the identification of how two variables correlate (children's learning experiences of AS and AS) represents a reasonable place to begin. Studying AS and the relation between meaningful variables is needed to reach a general theoretical framework. Kazdin (1999) stated that research productivity can be improved when it is focused on underlying mechanisms. The present study suggests that youths may be acquiring AS through verbal transmission of information (Rachman, 1977), and/or through operant conditioning processes (Ollendick, Vasey, \& King, 2001).

According to social learning theory, changes occur as a continuous interaction between an active organism and an active context (Ollendick \& Hirshfeld-Becker, 2002). Examining learning experiences associated with AS while giving consideration to intraindividual changes in the levels of AS is recommended for future research, since AS depends on many different factors and the complex interaction between them. Participants' intra-individual differences in interaction with contextual factors needs future research attention by conducting longitudinal studies and focusing on mechanisms and processes.

Field and Davey (2001) suggest that retrospective studies that examine etiological factors of fear tend to underestimate the influence of direct conditioning experiences. 
This prospective study with youths overcomes the selective memory bias of previous retrospective studies.

Limitations of this study include the use of a small sample size, representing a threat to the validity of the results. This was a main drawback given that an item analysis to explore, if the questions were validly tapping at the learning mechanisms, would have required a larger sample. Only self-report measures were incorporated, which represents another limitation of the study.

It is recommended that future prospective studies address learning experiences associated with AS using similar questions. Writing additional items for two additional learning mechanisms (i.e., modeling and punishment) is recommended to accurately assess learning mechanisms. An important next step would be to examine the extent that these findings replicate in a similar and larger sample. Increasing the sample size and testing each learning mechanism's internal consistency appears to be essential.

Additional forms of assessment are recommended for future studies, such as observation tasks in which parent and child interact in hypothetical experiences related to children's and parents' AS symptoms and learning situations. Finally, the incorporation of parental reports is recommended since parents may provide important information that could have complemented youths' self-reports. 
Albano, A. M., \& Silverman, W. K. (1996). Clinician Manual for The Anxiety Disorders Interview Schedule for Children DSM-IV (Child and Parent Versions). San Antonio, Texas: Psychological Corporation.

Bouton, M. E., Mineka, S., \& Barlow, D. H. (2001) A modern learning theory perspective on the etiology of panic disorder. Psychological Review, 108, 4-32.

Ehlers, A. (1993). Somatic and panic attacks: a retrospective study of learning experiences. Behaviour Research and Therapy, 31, 269-278.

Field, A. P., \& Davey, G. C. L. (2001). Conditioning models of childhood anxiety. In W. K. Silverman, \& P. D. A Treffers (Eds.), Anxiety disorders in children and adolescents: Research, assessment, and intervention (pp. 187-211). New York: Cambridge University Press.

Flesch, R. (1948). A new readability yardstick. Journal of Applied Psychology, 32, 221233.

Hayward, C., Killen, J. D., Kraemer, H. C., \& Taylor, C. B. (2000). Predictors of panic attacks in adolescents. Journal of the American Academy of Child and Adolescent Psychiatry, 39, 207-214.

Kazdin, A. E. (1999). Current (lack of) status of theory in child and adolescent psychotherapy research. Journal of Clinical Child Psychology, 28, 533-543.

Keller, M. B., Lavori, P. W., Wunder, J., Beardslee, W. R., et al, (1992). Chronic course of anxiety disorders in children and adolescents. Journal of the American Academy of Child and Adolescent Psychiatry, 31, 595-599.

Lee, S. W., Piersel, W. C., Friedlander, R., \& Collamer, W. (1988). Concurrent validity of the Revised Children's Manifest Anxiety Scale (RCMAS) for adolescents. Educational and Psychological Measurement, 48, 429-433.

Maller, R. G., \& Reiss, S. (1992). Anxiety sensitivity in 1984 and panic attacks in 1987. Journal of Anxiety Disorders, 6, 241-247.

Muris, P., Merckelbach, H., \& Meesters, C. (2001). Learning experiences and anxiety sensitivity in normal adolescents. Journal of Psychopathology and Behavioral Assessment, 23, 279-283.

Muris, P., Schmidt, H., Merckelbach, H., \& Schouten, E. (2001). Anxiety sensitivity in adolescents: Factor structure and relationships to trait and symptoms of anxiety disorders and depression. Behaviour Research and Therapy, 39, 89-100. 
Ollendick, T. H., \& Hirshfeld-Becker, D. R. (2002). The developmental and psychopathology of social anxiety disorder. Biological Psychiatry, 51, 44-58.

Ollendick, T. H., Vasey, M. W., \& King, N. J. (2001). Operant conditioning influences in childhood anxiety. In M. W. Vasey \& M. R. Dadds (Eds.) The developmental psychopathology of anxiety (pp. 231-252). London :Oxford University Press.

Pela, O. A., \& Reynolds, C. R. (1982). Cross-cultural application of the RevisedChildren's Manifest Anxiety Scale: Normative and reliability data for Nigerian primary school children. Psychological Reports, 51, 1135-1138.

Rachman, S. (1977). The conditioning theory of fear acquisition: A critical examination. Behaviour Research and Therapy, 15, 375-387.

Reiss, S. (1991). Expectancy model of fear, anxiety and panic. Clinical Psychologv Review, 11, 141-153.

Reiss, S., \& McNally, R. J. (1985). The expectancy model of fear. In S. Reiss \& R. R. Bootzin (Eds.), Theoretical issues in behavioral therapy (p. 107-122). New York: Academic Press.

Reynolds, C. R., \& Richmond, B. O. (1978). What 1 think and feel: A revised measure of children's manifest anxiety. Journal of Abnormal Child Psychology, 6, 271-280.

Schmidt, N. B., Lerew, D. R., \& Jackson, R. J. (1997). The role of anxiety sensitivity in the pathogenesis of panic: Prospective evaluation of spontaneous panic attacks during acute stress. Journal of Abnormal Psychologv, 106, 355-364.

Schmidt, N. B., Lerew, D. R., \& Jackson, R. J. (1999). Prospective evaluation of anxiety sensitivity in the pathogenesis of panic: Replication and extension. Journal of Abnormal Psychologv, 108, 532-537.

Schmidt, N. B., Lerew, D. R., \& Joiner, T. E. (2000). Prospective evaluation of the etiology of anxiety sensitivity: Test of a scar model. Behaviour Research and Therapy, 38, 1083-1095.

Silverman, W. K., Fleisig, W., Rabian B., \& Peterson, R. A. (1991). Childhood anxiety sensitivity index. Journal of Clinical Child Psychology, 20, 162-168.

Silverman, W. K., \& Ginsburg, G. S. (1998). Anxiety disorders. In T. H. Ollendick \& M. Hersen (Eds.), Handbook of child psychopathology (3rd., pp. 239-268). New York: Plenum. 
Silverman, W. K., \& Ginsburg, G. S., \& Goedhart, A. W. (1999). Factor structure of the childhood anxiety sensitivity index.. Behaviour Research and Therapy, 37, 903917.

Silverman, W. K., Goedhart, A. W., Barrett P., \& Turner, C. (2003). The facets of anxiety sensitivity represented in the childhood anxiety sensitivity index: Confirmatory analysis of factor models from past studies. Journal of Abnormal Psychology, II2, 364-374.

Silverman, W. K., Saavedra, L. M., \& Pina, A. A. (2001). Test-retest reliability of anxiety symptoms and diagnoses with anxiety disorders interview schedule for DSM-IV: Child and parent versions. Journal of the American Academy of Child and Adolescent Psychiatry, 40, 937-944.

Stein, M. B., Jang, K. L., \& Livesley, W. J. (1999). Heritability of anxiety sensitivity: A twin study. American Journal of Psychiatry, 156, 246-251.

Stewart, S. H., Taylor, S., Jang K. L., Cox B. J., Watt, M. C., Fedoroff, 1. C., et al. (2001). Causal modeling of relations among learning history, anxiety sensitivity, and panic attacks. Behaviour Research and Therapy, 38, 443-456.

Thomas, G., Hartley, D. R., \& Kincaid, P. J. (1975). Test-retest and inter-analyst reliability of the Automated Readability Index, Flesch Reading Ease Score, and the Fog Count. Journal of Reading Behavior, 7, 149-154.

Van Widerfelt, B. M., Siebelink, B.M., Goedhart, A. W., \& Treffers, P. D. A. (2002). The Dutch Childhood Anxiety Sensitivity Index: Psychometric properties and factor structure. Journal of Clinical Child and Adolescent Psychology, 31, 90-100.

Watt, M. C., \& Stewart, S. H. (2000). Anxiety sensitivity mediates the relation between childhood learning experiences and elevated hypocondriacal concerns in young adulthood. Journal of Psychosomatic Research, 49, 107-118.

Watt, M. C., \& Stewart, S. H., Cox, B. J. (1998). A retrospective study of the learning history origins of anxiety sensitivity. Behaviour Research and Therapy, 36, 505525.

Weems, C. F., Hammond-Laurence, K., Silverman, W. K., \& Ginsburg, G. S. (1998). Testing the utility of the anxiety sensitivity construct in children and adolescents referred for anxiety disorders. Journal of Clinical Child Psychology, 27, 69-77.

Whitehead, W. E., Bush, C. M., Heller, B. R., \& Cost, P. T. (1986). Social learning influences on menstrual symptoms and illness behavior. Health Psychology, 5, 13-23. 
Whitehead, W. E., Morrison, A., Crowell, M. D., Heller, B. R., Robinson, J. C.,

Benjamin, C., \& Horn, S. (1992). Development of a scale to measure childhood learning of illness behavior. Western Journal of Nursing Research, 14, 170-185. 


\section{LEARNING EXPERIENCES QUESTIONS}

Assessor: identify and point to the items the child answered "A Lot" to on the CASI.

Then say the following statement while pointing at the items the child answered "A Lot" to:

I want to go back to all the items you answered "A Lot" to on this questionnaire and ask you whether certain things happen to you when these feelings happen to you "A Lot"?

Please use one of these three words: "None", "Some", or "A Lot"

Assessor: For the items marked as "A Lot" on the CASI, ask the Learning Questions. For example, "When you don't want other people to know when you feel afraid and when you feel 'shaky' and get scared ... do you skip your schoolwork, homework, or jobs around the house?"

\section{Learning Questions}

... do you skip your schoolwork, homework, or jobs around the house?

... do you get special things. Like special foods or presents?

... do you skip physical activities. Like sports, soccer, or running?

... do you skip activities with family or friends, like birthday parties?

... do you get to do things that you are usually not allowed to do like watching TV for a really long time or staying up late at night?

... do your parents tell you that they worry about you feeling this way?

... do your parents take you to see a doctor?

... do your parents give you medicine?

... do your parents seem scared or nervous about how you are feeling?

... do your parents tell you that you can get really sick because you feel this way?

None Some A Lot

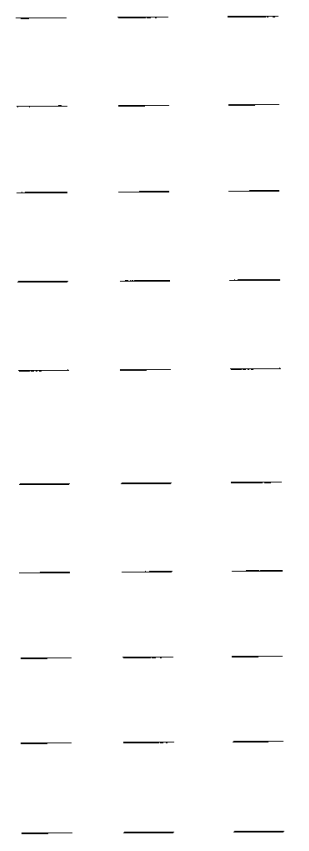


Table 1

Composition of Learning Experiences Questions

Item

1- do you skip your schoolwork, homework, or jobs around the house?

2- do you get special things. Like special foods or presents?

3- do you skip physical activities. Like sports, soccer, or running?

4- do you skip activities with family or friends, like birthday parties?

5- do you get to do things that you are usually not allowed to do. Like watching TV for a really long time or staying up late at night?

6- do your parents tell you that they worry about you feeling this way?

7 - do your parents take you to see a doctor?

8- do your parents give you medicine?

9- do your parents seem scared or nervous about how you are feeling?
Learning Mechanism

Negative Reinforcement

Positive Reinforcement

Negative Reinforcement

Negative Reinforcement

Positive Reinforcement

Verbal Transmission of Information

Positive Reinforcement

Positive Reinforcement

Verbal Transmission of Information

Verbal Transmission of Information 
Table 2

Response Frequencies, Mean Scores, Standard Deviations, and Correlations Between Anxiety Sensitivity and the Learning Experiences Questions

Response Frequency

\begin{tabular}{|c|c|c|c|c|c|c|}
\hline \multirow{2}{*}{ Item } & & \multirow[b]{2}{*}{$M$} & \multirow[b]{2}{*}{$S D$} & \multirow{2}{*}{$\begin{array}{l}\text { Anxiety } \\
\text { Sensitivity } \\
\text { (CASI) }\end{array}$} \\
\hline & None & Some & A Lot & & & \\
\hline $\begin{array}{l}\text { I- do you skip yout schoolwork. homework, or } \\
\text { jobs around the house? }\end{array}$ & 18 & 12 & 3 & 1.55 & .67 & $.37^{*}$ \\
\hline $\begin{array}{l}\text { 2- do you get special things. Like special foods or } \\
\text { presents? }\end{array}$ & 23 & 6 & 4 & 1.42 & .71 & .33 \\
\hline $\begin{array}{l}\text { 3- do you skip physical activities. Like sports, } \\
\text { soccer, or running? }\end{array}$ & 16 & 14 & 3 & 1.61 & .66 & .28 \\
\hline $\begin{array}{l}\text { 4- do you skip activities with family or friends. } \\
\text { like birthday parties? }\end{array}$ & 22 & 11 & 0 & 1.33 & .48 & .07 \\
\hline $\begin{array}{l}\text { 5. do you get to do things that you are usually not } \\
\text { allowed to do. Like watching TV for a really long } \\
\text { time or staying up late at night? }\end{array}$ & 17 & 13 & 3 & 1.58 & .66 & -.07 \\
\hline $\begin{array}{l}\text { 6- do your parents tell you that they worry about } \\
\text { you feeling this way? }\end{array}$ & 7 & 15 & 11 & 2.12 & .74 & $.37^{*}$ \\
\hline 7- do your parents take you to see a doctor & 9 & 11 & 13 & 2.12 & .82 & $44^{*}$ \\
\hline 8- do your parents give you medicine? & 12 & 10 & 11 & 1.97 & .85 & $.39^{*}$ \\
\hline $\begin{array}{l}\text { 9. do your parents seem scared or nervous about } \\
\text { how you are feeling? }\end{array}$ & 10 & 14 & 9 & 1.97 & .77 & .33 \\
\hline $\begin{array}{l}10 \text { - do your parents tell you that you can get } \\
\text { really sick because you feel this way? }\end{array}$ & 15 & 6 & 12 & 1.91 & .91 & .28 \\
\hline
\end{tabular}

Note: CASI $=$ Childhood Anxiety Sensitivity Index .

$N=33$

$* P<.05$. 